Do challenges to students' beliefs, values and behaviour within social work education, have an impact on their sense of well-being?

Mel Hughes

Diploma in Social work (DipSW)

Masters in Social Work (MSW)

Post qualifying Practice educator Award

Lecturer in Social work

Bournemouth University

Centre for Social work and social policy

Royal London House

Christchurch Road

Bournemouth

BH1 3LT

England

mhughes@bournemouth.ac.uk 


\title{
Do challenges to students' beliefs, values and behaviour within social work education, have an impact on their sense of well-being?
}

\begin{abstract}
This paper draws on the findings of a unitary appreciative inquiry which aimed to illuminate the unique experiences of five student social workers approaching qualification. It identifies the impact social work education had on their whole selves; their beliefs, values and behaviour and the impact of this learning on their sense of well-being. The findings are summarised and presented within this paper as five individual profiles including the participants' own representations of this impact. The study found that their well-being was affected significantly by changes to their sense of self; changing relationships with others and heightened awareness of oppression and injustice. Whilst all reported positive outcomes resulting from personal, academic and professional achievement, all shared examples of where their learning had impacted negatively on relationships with friends and family. This had led to internal conflict as they sought to adjust to their new ways of thinking and the implications for their behaviour past and present. The participants believed that this was best supported within social work education when values and behaviours were modelled by staff; when educators acknowledged and understood the potential impact of learning and when networks for sharing experiences, seeking support; and enabling slow, developmental change were available.
\end{abstract}

Key words: well-being, whole person, unitary appreciative inquiry, social work education, impact, transformative learning 


\section{Do challenges to students' beliefs, values and behaviour within social work education, have an impact on their sense of well-being?}

\section{Introduction}

This paper draws on the findings of a unitary appreciative inquiry (Cowling 2001, 2004a, 2004b, 2005) which aimed to illuminate the unique experiences of the student social work participants, in relation to the impact that they believe social work education has had on their whole selves; their beliefs, values and behaviour and the impact of this learning on themselves. It represents as close a picture as possible of their experiences and the implications of their experience for social work education. The research is based on a holistic view of learners that recognises that their identity goes beyond that of student or social worker. It acknowledges the multiple aspects of their 'whole selves' such as physical, spiritual and emotional and of the interconnectedness between them and their environment. It recognises that challenges and changes to their beliefs, values and behaviour during their education, may have a significant impact on their whole selves and their lives. The research study is underpinned by educational theory developed by Rogers (1969), Knowles (1984) and Mezirow (1996) amongst others as they recognise the proactive, individualised processes of learning where knowledge is internalised and made sense of through the lens of our previous experiences. As such, learning is likely to affect all aspects of our lives as our knowledge and outlook on life changes. Whilst the research study focussed on the broader question of what the impact of this learning had on their lives, a range of evidence emerged regarding the impact of their learning on their sense of well-being. The insight, learning, knowledge and practice development gained by 
recognising and appreciating their perceptions is explored within the wider context of social work education. Options for acknowledging and supporting students through this transition are discussed.

\section{Background}

As a lecturer on an undergraduate social work programme, I wanted to explore whether the focus within social work education on values, beliefs and behaviour and the need to align these with the values of the profession, have an impact on the person outside of the classroom. Gardner (2001:29) for example comments that 'if people start to change their views about gender issues in class, this is likely to affect how they see gender issues at home so affect significant relationships.' My professional values as a social work practitioner are to recognise the person within the context of their lives; to seek an understanding of their experiences from the person themselves and to negotiate with them, as much as possible regarding the most appropriate way to intervene. As this approach is based on respect and on viewing individuals as unique and their own best expert, I have sought to transfer this approach and value base to my role as educator when working with students. The study illuminates these experiences by focussing on students completing their undergraduate social work education. The students shared a number of experiences which can increase our insight into the impact of their learning experience on their sense of well-being.

\section{Well-being}

Well-being as identified within this study relates to a student's sense of well-being and as such includes the different aspects of physical, mental and social well-being 
referred to by the Ottawa Charter for health promotion (1986). The study did not seek to differentiate between these as it took a holistic approach which seeks to view the person as a whole and not as reducible parts. This is congruent with the approach the study used of unitary appreciative inquiry which seeks to gain the 'deepest possible understanding of (an experience) and its relationship to the person's life' (Cowling 2004b:289). The Ottawa Charter states that 'to reach a state of complete physical, mental and social well-being, an individual or group must be able to identify and realize aspirations, to satisfy needs, and to change and cope with their environment.' The participants in the study expressed an overwhelmingly positive outcome to their education and the impact on their sense of well-being in terms of meeting aspirations and satisfying need but expressed difficult experiences during the process of adapting to their environment and to the changes in self.

\section{Context}

Social work education, as with other professional education is not restricted to the passive acquisition of knowledge but must also focus on the personal and professional development of skills and values and the application of that learning to the person's practice. The aim of social work education is to improve the quality of the workforce through the development of competent, confident, self aware and reflective practitioners who are able to cope with the pressures, demands and risks of the work whilst maintaining a professional value base which places service users and carers at the heart of the process.

To achieve this, contemporary social work education and social work practice is guided in England by recommendations by Lord Laming (2003, 2009); The Social 
Work Taskforce (2009) and The National Occupational Standards for Social Work (2002). These place an increased emphasis on the individual; on personal qualities; on the need to critically reflect and the increasing use of self. As Cournoyer (2000:35) states 'social work practice involves the conscious and deliberate use of oneself; 'you become the medium through which knowledge, attitudes and skills are conveyed' (cited in Reupert 2007:107). The Social Work Taskforce makes recommendations for entry into the profession which emphasise the need for social work students to have particular personal qualities such as 'insight, common sense, confidence, resilience, empathy and the use of authority’ (2009:17). Service users and carers have emphasised the need for social workers to possess personal qualities such as warmth, empathy, understanding and who are punctual, reliable and trustworthy (Skills for Care 2002). The National Occupational Standards for social workers in England include a number of value requirements such as the need for social workers to have an 'awareness of own values, prejudices, ethical dilemmas, conflict of interests and implications for practice’ (TOPSS 2002:63).

Whilst some emphasis has been placed on recruiting students who already possess these qualities and values, the role for social work education is to assess individual students' values, beliefs and behaviours and to enable them to align these with those of the profession or prevent them from qualifying if they do not. This brings into scrutiny, personal aspects of a person's sense of self and identity which will inevitably have an impact on their whole selves and potentially on their sense of well-being.

There is evidence to demonstrate that significant changes do take place as students experience a range of catalysts which lead to shifts in their beliefs, values and frames 
of reference (Argyris and Schon 1974, Mezirow 1996, Johns 2005). There has been a significant increase in the range of social work literature relating to teaching and enabling the development of skills in critical reflection (Fook 2004, Gould and Baldwin 2004, White et al 2006 amongst others) which can help students to make sense of these shifts and changes. Exploration into the impact of these changes, transformations and consolidations on the person themselves however, remains minimal. For those participating in this study, the shifts in values were perceived as having a significant and at times life changing impact. The transformative nature of social work education is touched on by Collins et al (2010) when identifying causes of stress amongst social work students but other than this study, it seems that the literature is limited to research which has focussed only on aspects of a person's life such as reasons for retention (Hafford-Letchfield 2007); parenting (Green-Lister 2003) and spiritual wellbeing (Kamya 2000). There has been little focus on the whole person within the context of their lives and the impact that changes to values, beliefs and behaviour may have on their sense of well-being.

Perhaps nearer to the mark is the literature relating to social work education and personal growth as this recognises changes to the person themselves. Pardeck and McCallister (1991:383) identified that 'personal growth and development as well as intellectual growth of students are major goals of social work education' however their assessment in the early 1990's, of student's personal growth through completion of self expression, generalised contentment and self esteem scales, suggested that undergraduate social work education had 'little or no effect on the personal growth or development of students' (p385). They compare this to a study by Cournoyer in 1983 where social work students were assessed as having a decrease in assertiveness after 
their social work training (as a result of what Cournoyer termed 'battered student syndrome'). More recent studies such as Collins et al (2010) report a high level of students feeling they were a 'person of worth' and yet over a quarter of the students in their study reported negative attitudes about themselves such as feeling dissatisfied with themselves, not feeling proud of the people they were and not feeling that they were as good as other people. This poses the question of whether we are losing sight of the person (the student); their perceptions, needs and well-being within this process. Seeking to recognise and understand the impact that the process of learning and transition has on the whole person by illuminating their experience, has the potential to improve both the experience for students and the outcomes for the profession.

\section{Methodology}

The study used a unitary appreciative inquiry (UAI) to gain these insights and perspectives. UAI is a relatively new qualitative approach still being developed by W. Richard Cowling originally for use within mental health nursing research and practice. Cowling argues that by understanding and appreciating life patterns, wholeness and uniqueness, practitioners can seek to improve 'the lives of individuals, families, groups and communities’ (2005:94). Whilst it seeks patterns which reflect the wholeness, essence and uniqueness of a particular individual or group, reflection on these representations and patterns 'can provide a way of understanding human life, conditions and situations' (2001:35). As such they can be used to inform our understanding of the particular context as well as the particular person. UAI seeks to achieve this understanding by generating and collecting a range of data regarding the person or group's experience; representations of that experience using methods of creative expression e.g. music, art, storytelling; and the participants' views on the 
implications of that knowledge for themselves and others. It creates a synopsis of this data in the form of an appreciative profile which can then be used for further reflection and analysis by participants, the researcher and others.

\section{Method}

The five participants were self selecting from the final year cohort of the undergraduate Social work degree for which I am lecturer. As the participants were known to me, a number of factors relating to insider research (Mercer 2007, Coghlan 2006, Gunasekara 2007, Darra 2008) and informed consent (Miller and Crabtree 1999, Malone 2003 ) were considered when seeking ethical approval and these were shared with potential participants prior to volunteering. Participants had the opportunity to generate, view and amend data presented within the findings to check authenticity and to further anonymise or generalise if they wished.

Participants attended an individual audio recorded interview. This was guided by certain themes: gaining a sense of the person; the impact of social work education on themselves and the implications of this impact. This was followed by a one day group workshop where participants collaborated to develop representations of their experiences. This was through the use of objects, imagery, music, mind maps and verbal discussion. Within the course of the day, participants shared their own reflections and representations and encouraged and enabled each other to analyse and reflect on their experiences. they worked together to form the basis of a group representation in the form of a digital story (a series of visual images with an audio commentary). The story was further developed following the researcher led workshop using their ideas and images and the words of the participants from their audio 
interviews. It was then shown to the participants to check accuracy and issues of anonymity but also as a catalyst for further analysis and reflection. It was then shared with other members of the participants' cohort for feedback on the meaning and resonance for them.

\section{The findings}

The research findings include a range of materials and documents to present as close a picture as possible to the actual experience of the participants. The study did not seek to be representative of the cohort but to illuminate unique experiences. These are presented together to create a unitary appreciative profile (Cowling 2004) of the impact of qualifying social work education on a person's beliefs, values and behaviour. The findings in relation to the participants' sense of well-being are summarised and presented within this paper, as five individual profiles including the participants' own representations. Their perceptions and views are shared within the discussion.

\section{Individual profiles (anonymised)}

\section{The impact for Assad}

Assad identifies himself as a Black, Muslim, bi-lingual male with a multi-cultural background. His experience of social work education is characterised by significant challenges and changes to his own values and beliefs. He lives his life under the direction of his Muslim values but explains how many of his cultural beliefs were challenged through his learning on the social work degree. This in turn led him to question aspects of his culture and his own behaviour. Changes to his beliefs and values caused conflict for Assad with family and friends and within himself. His 
transition involved developing a value base that could be congruent to both his personal, religious, cultural and professional beliefs and values, which he feels he was successful in achieving. He believes that the emotional impact was negative at times but has had a positive outcome. 'I think (this course) is the best thing I have done. That's all I can say. I have learnt a lot. It’s made a big difference'.

Assad chose a photo of his and a friend's hands on the Mission Impossible plaque on the walk of fame and his bike as representations of the impact on him of social work education.

The hands are a photo of me and a friend I made on the course.

It symbolises difference

The hands symbolise friendship

Mission impossible is how it feels sometimes

I used this bike to cycle to Uni everyday

The bike represents a journey

There are times when it's hard work going up hill

Sometimes it's a breeze, freewheeling down hill

Over the three years I have made changes and repaired parts.

It has a new wheel.

It's the same bike but its parts have changed

I’m the same person but I've adapted.

\section{The impact for Vicky}


Vicky identifies herself as a white British female in her early twenties, from the North of England. She was 18 at the start of her social work education and she identifies herself as having changed a lot during this time. For her, the transition is one of becoming; becoming an adult, a professional, a social worker, a Feminist. The transition has been influenced by moving away from home for the first time, becoming more independent, developing new friendships, experiencing difficulties with flat mates, becoming homeless for a short time, fleeing a threatening and potentially violent relationship and becoming more politically aware. The impact of this transition on Vicky's sense of well-being was substantial as she experienced many causes of instability over the three years and the gains came with many losses. I'll always love my friends and where I’m from but I hardly go back home now. I don’t particularly feel at home there anymore and I didn’t expect that to happen. I feel quite worried because I don't know what to do with myself now'

Vicky shared the same photo as Assad of her's and his hands on the Mission Impossible plaque on the walk of fame and a 'thinking of you' card as representations of the impact on her of social work education.

I spent my $21^{\text {st }}$ birthday at home

There was a moment when I realised, I'd grown apart

I didn’t really belong anymore

The card was from my Mum

'love you, miss you'

It was significant that she needed to write a card.

It was because I didn’t go home as much 
I chose the photo of the hands together with 'Assad' when thinking about today

It's about new friendships

Accepting difference

\section{The impact for Terry}

Terry identifies himself as 'a 45 year old, white British male, who is an atheist, has adopted what he feels are working class values as opposed to his parents middle class ones and who believes strongly in fairness, equity and that social justice is his core value'. He reflects deeply on the impact of his childhood experiences on his beliefs, values and behaviour and on the impact of social work education in shaping these further. He feels that he has experienced change and provides examples of analysing his previous experiences and behaviours following particular areas of learning within the degree. This has had an impact on current relationships such as that with his father which has become more open. His sense of well-being was strengthened in many ways as he made sense of his past experiences and discovered a role and profession he felt he was good at. The process however was difficult. 'The learning experience as a whole has been really enjoyable. It sort of gives you resilience but it is so damned hard. It really is hard work. When you finish you'll think God have I earned this. It's going to be a bit of a personal milestone to me.'

Terry chose a song: The Stranglers: No More Heroes and a Sully toy from the film Monsters Inc as representations of the impact on him of social work education.

I was a really huge Stranglers fan 
There's a line

'Whatever happened to all the heroes?

All the Shakespearoes, they watched their Rome burn

Whatever happened to all the heroes?'

That would be my representation of the impact and knowing what I want to be

Sully lives in my car

When I'm driving kids when I'm at work, they can play with him

A kid I used to work with gave him to me, it was a gift

I saw him recently and was able to say I still had him

I have a long drive into Uni from home

I have spent a lot of time in the car

Sully is an unconditional listener

\section{The impact for Jessica}

Jessica identifies herself as a white British, able bodied female in her early thirties.

Her experience was influenced by the need to work full time throughout her three year degree and she describes feeling quite isolated at times from the year group and struggled to 'find her place'. She acknowledged the pressure she places on herself to do well and identified the impact of this stress, in particular from placement on herself; her relationships and on her sense of well-being.

Jessica chose a clock, a diary and a $30^{\text {th }}$ birthday card as representations of the impact on her of social work education.

Three years of diaries and a clock 
Everything is part of a schedule and is organised

I find it quite comforting

Knowing what I am going to be doing for the next year

Having it all planned out

It represents the need to juggle and manage everything

I had a significant birthday and my niece was born

I can think back to that day and I know what assignment I was working on

I could only allow a short amount of time to celebrate.

I had to get back to my assignment

I'm not sure about not knowing what's coming next

I’m programmed now to work at this pace, I can’t stop now!

\section{The impact for Linda}

Linda identifies herself as female, Scottish British, 42. Linda started the course with a strong sense of her identity and her values and a political interest and awareness. She didn't expect any huge changes to self during her social work education but believes that small changes have occurred. Change for her has been about becoming more open minded (and recognising that she wasn't as open minded as she had thought before), becoming more reflective and considered in her thinking and reflections and communicating more openly. She reflects on the impact this has had on her practice but also on her relationships and friendships. 'My friends think I'm more open, which can only be a good thing'. 
Linda chose two albums: The Streets: It was supposed to be easy and Elbow: Leaders of the free world as representations of the impact on her of social work education.

The Streets: 'it was supposed to be easy'

So much of this album is representative for me

The title fits with how I feel

The lyrics are a social commentary

He lays it bare - is honest

He thanks everyone who has ever 'dissed' him for giving him focus I've listened to the Streets and Elbow so often during the 3 years.

It's become my soundtrack

\section{Discussion}

All of the participants had experienced what Mezirow describes as perspective transformation or a change to their frame of reference, to one which is 'more inclusive, differentiating, permeable (open to other view points), critically reflective of assumptions, emotionally capable of change and integrative of experience' (Mezirow 2000:19 cited in Taylor 2007). For all of the participants, this had in part, impacted positively on their sense of well-being. They expressed feelings of confidence, self belief, satisfaction and a feeling that their beliefs and behaviours were fair and just. There were many examples of challenging injustice and oppression for example which gave the participants a sense of satisfaction as well as examples of achievement gained through academic and professional success and which led to increased self esteem. 
The process of transition however; of becoming more aware, critically reflective of assumptions and open to other viewpoints had led to some negative experiences and outcomes that affected their sense of well-being and quality of life. Participants described feelings of guilt, shame, frustration, anxiety, of losing a sense of belonging and identity, difficult family relationships; losing friendships and experiencing stressful situations. This was represented most strongly by the participants when expressing changes to their values and outlook and the impact on relationships with friends and family. Some of these experiences and the implications for their wellbeing are shared here.

\section{Personal values}

The primary focus of the research study was to identify the impact on the students' lives of the focus of social work education to enable students to align their values with those of the profession. Linda and Jessica felt that their values had remained unchanged, due as they saw it to a congruence between their personal values and the professional ones they were encouraged to develop 'I’ve retained most of my personal values and beliefs. My foundation is still the same. How I see things has changed'. As Jessica said 'I think probably, before I would challenge things but now I challenge things and I have a better argument'. For them, the change had led them to feel more confident and assured in their own beliefs which satisfied a need for them and added to their sense of well-being.

Terry and Assad talked of how their value base changed as their knowledge and awareness increased. They both gave examples of this leading them to question old behaviour. As Terry said 'There’s this raft of knowledge about anti-racism that has 
really changed my value base. I had a few black friends at school but I'd be the first to say we used to be pretty abusive to each other. I want to go back and apologise to people to say sorry for what I've said. I feel ashamed and really guilty'.

Assad also used his new learning to question old behaviours 'My uncle I remember when I was young, now I understand that he was suffering from Schizophrenia but then, they said he had an evil spirit so nobody gave him any proper help or medication. They used to let him out in the sun all day. I regret that now, I wish I could challenge it. I did ask my Aunt one day, why did we treat him that way, he needed help. She doesn’t have any answers'.

The desire to go back and change previous actions was a common one amongst the participants which seemed to evidence the increase in awareness experienced by the participants as their new knowledge led them to reinterpret the meaning they had attached to previous experiences and events. For Terry and Assad, this desire formed part of their process of adjusting to a new awareness and knowledge. It caused uncomfortable feelings of shame and guilt for Terry and frustration and regret for Assad as they viewed their 'old selves' through the lens of the new. This created an inner conflict which affected their sense of well-being as they sought to adjust to their new outlook and make amends for their old behaviour. They both commented however on this change being for the better. The outcome impacted positively on their self esteem and confidence which were key factors in maintaining a sense of wellbeing.

\section{Relationships with others}


For all of the participants, shifts in their outlook, beliefs, values and behaviour had an impact on their relationships with others. All identified their relationships with friends or family as important to their sense of self and to their well-being and as a source of stability, support and identity. All however experienced changes to these relationships as a direct result of their social work education resulting in conflict, instability, disruption to social support networks and to their sense of identity and belonging.

Terry explained that his learning had led him to ‘see oppression’ everywhere and of the need to challenge this. 'People send you jokes and stuff and I had to say to my nephew last week, that's just bang out of order that is. Send me something funny, not that crap'. All of the participants talked of challenging friends, family and colleagues regarding what they felt to be discriminatory or oppressive comments. For Jessica with strong family support, this was accepted and she felt that her family had been open to the challenges and showed a willingness to 'get it right'. For Assad and Vicky, this had lost them friendships, in part due to their shifting values that meant they no longer wanted to spend time with certain people. As Vicky said, ‘they hadn’t changed, I had'. For Assad, it had caused difficulties in family relationships as his heightened awareness had caused him to question beliefs within his family. 'In my family my nephew said he was gay. Every member of the family was angry. I told them, it is his choice. They were not happy with me. Why are you supporting him? Why are you encouraging him? Including my own sister, she didn't talk to me for a while'.

Vicky describes losing her sense of belonging. For her this led to significant feelings of instability and an unclear sense of who she was. It led to fewer visits home which also reduced her support networks which would ordinarily have maintained her sense 
of well-being. She links this with being less able to deal with difficulties which then presented during her time on the course but also as a factor in developing resilience, independence and maturity.

The impact had been stressful for all of those describing these experiences, a factor acknowledged by Collins et al (2010) who comment on the transitional nature of professional courses being a likely factor in why social work and nursing students have been shown to have higher levels of stress than more traditional, non vocational students. For all of the participants the impact on their relationships with friends, family and colleagues had resulted from shifts in their own beliefs and values but also their unwillingness to ignore comments, jokes and behaviour and their need to challenge oppression and discrimination when they saw it. Their social work education had affected not only their beliefs and values but also their behaviour outside of the classroom and the practice environment. All of them commented that their education had taught them to 'speak up'. What was striking about the impact expressed by the participants, was that despite some very difficult experiences and conflict (both internally and externally), this was buffered by the positive outcomes of their learning and a sense that their increased knowledge and understanding had 'made them a better person'. This view was supported by many of the participants' peers when sharing the representations created within the study, with them. Despite stressful experiences and difficult periods of transition, all of the participants reported this to be a positive change but also a permanent one, As Assad commented, 'it's a long lasting change whether I like it or not!'

\section{Implications for social work education}


From my perspective, listening to the participants’ stories and representations, I discovered many aspects of their lives and experiences that I had now known about which greatly increased my insight into their experiences; their processes of learning and their transition from student to professional. I concluded that it is important to recognise issues that have the potential to impact on a student's well-being both in terms of our responsibility to provide a duty of care but also to enable them to make sense of their learning within the context of their own lives. It provides the opportunity to enable the students' learning to be in depth and meaningful by using their whole selves as a resource (Rogers 1969, Knowles 1984 and Mezirow 2000) but also in enabling them to adapt to these changes in a way that satisfies their needs and maintains a sense of well-being.

How we achieve this within social work education is perhaps at times assumed to be the domain of the practice placement and the role of the practice educator. The participants however argued that the focus should be as strong within university based education. One of the participants stated that she would have benefitted from one to one supervision within university based education rather than just on placement 'The lecturer always said if I had any problems to come and see them but I've never really had any big problems. Placement is really good because you get to sit down with somebody and it may be a little thing but if it's not dealt with it can become a big thing. It would have been nice to have had more time to just talk about your experiences and to reflect with someone else'. The challenge of social work educators is to develop strategies for students to satisfy this need within the available resources. Whilst practice learning support is key, the role of the university based educator is paramount in enabling student social workers to make sense of their learning in order 
to become the insightful, confident, resilient and empathic social workers the profession requires. It was important to the participants for educators to model these qualities.

In my own practice as an educator this has led to the exploration of a number of different approaches. Some suggested by the participants and others as my response to the issues they raised. The next step will be to evaluate the effectiveness of these in supporting students with the transformative nature of social work education and in minimising the negative impact on their sense of well-being. These have or will include an increased focus within the curriculum across the year groups on preparing students for the potential impact; sharing strategies for dealing with stress and stressful situations; encouraging and supporting the development of peer support, mentoring and places to share experiences; and providing support for difficulties when needed. The goal of such strategies is not only to maintain the students' sense of well-being within social work education and as qualified social workers, but also to impact positively on their lives as a whole.

\section{Conclusions}

Whilst the research focussed on the unique experiences of just five participants, the aim of a unitary appreciative inquiry is to learn from these unique experiences to enhance our understanding of a particular context, in this case social work education. There are several conclusions that we can draw from the experiences represented in this paper that can inform our understanding of this impact. For the participants, there had certainly been an impact on their beliefs, values and behaviour as a result of their social work education. In most cases this was a process of increasing their awareness 
and opening their eyes to what was out there rather than fundamental changes. As Jessica said’ I always used to challenge but now I can say because...' or as Vicky explained, she just hadn't realised the extent of certain issues. For Assad, some of his beliefs had fundamentally changed such as beliefs regarding homosexuality and women's roles as a result of being more open to other people's views and experiences. All of the participants talked of being more open; more empathic; more aware and having what Mezirow (2000) would describe as a more permeable frame of reference having become more open to changes and challenges to their thinking.

For all of the participants however, this had impacted negatively on some of their relationships with friends and family and had led to internal conflict as they sought to adjust to their new ways of thinking and the implications for their behaviour past and present. This had impacted negatively on their well-being as for them, factors such as having a strong sense of identity, good support and social networks, stability, a sense of belonging and good relationships with others were key. The participants believed that whilst the process of change had at times been difficult and had impacted significantly on their lives, the outcome was positive. They felt that the difficult aspects of the transition were best supported within social work education when values and behaviours were modelled by staff; when educators acknowledged and understood the potential impact of their learning on themselves and when networks for sharing experiences, seeking support; and enabling slow, developmental change were available. 


\section{References}

Argyris, C and Schon, D (1974) 'Theory in Practice: Increasing Professional Effectivenes’s. Jossey-Bass Classics: San Francisco

Coghlan, D 2007 Insider Action Research doctorates: Generating actionable knowledge. Higher Education 2007, 54, 293-334

Collins, S, Coffey, M, Morris, L (2010) 'Social work students: Stress, support and well-being’. British Journal of Social Work 2010, Vol 043, No 40, pp 963-982

Cowling, W.R (2001) ‘Unitary Appreciative Inquiry’. Advances in Nursing Science, Vol 23, No 4, pp 32-38

Cowling, R (2004a) 'Pattern, Participation, Praxis and Power in Unitary Appreciative Nursing Perspective’. Advances in Nursing Science. Vol 27, No 3, pp 202-214

Cowling, R (2004b) 'Despair: A Unitary Appreciative Inquiry’. Advances in Nursing Science. Vol 27, No 4, pp 287-300

Cowling, R (2005) ‘Despairing Women and Healing Outcomes: A Unitary Appreciative Inquiry’. Advances in Nursing Science. Vol 27, No 4, pp 287-300

Darra, S 2008 Emotion Work and Ethics of Novice Insider Research. Journal of Research in Nursing 2008; Vol 13; 251-261 
Fook, J (2004) 'Critical Reflection and transformative possibilities in Social Work in a Corporate era' eds Davies, L and Leonard, P. London: Ashgate

Gardner, F (2001) 'Social work students and self awareness: How does it happen?' Reflective Practice 2001, Vol 27, No 14)

Gould, N and Baldwin, M (2004) 'Social Work, Critical Reflection and the Learning Organisation'. London: Ashgate

Green Lister, P (2003) “'Its like you can’t be a whole person, a mother who studies’. Lifelong learning: mature women students with caring commitments in social work education’. Social Work Education. Vol 22, no 2, 2003. Carfax Publishing

Gunesekara, C 2007 Pivoting the Centre: Reflections on undertaking qualitative interviewing in academia. Qualitative Research 2007, Vol 7, 461-475

Hafford-Letchfield, T (2007) 'Factors affecting Retention of learners following a degree in Social Work at a University in the South East of England'. Learning in Health and Social Care. Vol 6, No 3, pp 170-184

Heron, J (1996), ‘Co-Operative Inquiry: Research into the Human Condition’. London: Sage Publications.

Johns, C (2005) Dwelling with Alison: A reflection on expertise. Complimentary Therapies in Clinical Practice (2005) Vol 11, pp 37-44 
Kamya, H (2000) 'Hardiness and Spirituality among Social Work Students:

Implications for Social Work Education'. Journal of Social Work Education. Vol 36, No 2. Spring / Summer 2000

Knowles, M (1984) 'The Adult Learner: A Neglected Specie’s. $3^{\text {rd }}$ ed Gulf Publishing Lord Laming: Chair, (2003) 'The Victoria Climbie inquiry report of an inquiry by Lord Lamin'g. Accessed at www.dh.gov.uk/en/Publicationsandstatistics/.../DH$\underline{4008654}$

Lord Laming (2009) 'Protection of children in England: A progress report'. Accessed at www.publications.education.gov.uk/eOrderingDownload/HC-330.pdf

Malone, S 2003 Ethics at home: informed consent in your own backyard. Qualitative Studies in Education, Nov-Dec 2003, Vol 16, No 6, 797-815

Mezirow, J. (1996). ‘Contemporary paradigms of learning’. Adult Education

Quarterly, Vol 46, No 3, pp 158-172

Miller, W.L and Crabtree, B.F 1999 Depth Interviewing in Crabtree, B.F and Miller, W. L 1999 (Editors) Doing Qualitative Research (2 ${ }^{\text {nd }}$ edition) London: Sage

Pardeck, J.T and McCallister, R.L (1991) 'The Effects on Undergraduate Social Work Education on the Personal Growth and Development of Students'. Social Work Education Vol 11, pp 382-387 
Reupert, A (2007) ‘Social Worker’s Use of Self’. Clinical Social Work Journal. 2007, No 35, pp107-116

Skills for Care (2002) 'Statement of Expectations of People using services and their carers’ Accessed

http://www.niscc.info/content/uploads/downloads/workforce_dev/NOS_health_social/ $\underline{\text { Statement_expectations.pdf }}$

Social Work Taskforce (Dec 2009) 'Final Report of the Social work taskforce'. Accessed at www.dcsf.gov.uk/swtf

Tam, M (2004) ‘Using Student’s Self Reported Gains as a Measure of Value-added’. Quality in Higher Education, Vol 10, No 3, pp253-260

Taylor, E (2007) ‘An Update of Transformative Learning Theory: A Critical Review of the Empirical Research (1999 - 2005)’. International Journal of Lifelong Education,. Vol 26, No 2 Mar-Apr 2007, pp173-191

TOPSS UK Partnership (May 2002) 'National Occupational Standards for Social Work'. Accessed 15/2/10 at http://www.skillsforcare.org.uk/developing_skills/National_Occupational_Standards/s $\underline{\text { ocial_work.aspx }}$

White, S, Fook, J and Gardner, F (2006) 'Critical Reflection in Health and Social Care’. McGraw Hill 
World Health Organisation (1986) 'The Ottawa Charter for health promotion'. First International Conference on Health Promotion, Ottawa, 21 ${ }^{\text {st }}$ November 1986.

Accessed 20/9/10 at

http://www.who.int/healthpromotion/conferences/previous/ottawa/en/index.html 